\title{
Saúde Mental na Atenção Básica: perspectivas de profissionais da Estratégia Saúde da Família no Nordeste do Brasil
}

\author{
Mental Health in Primary Care: perspectives of professionals \\ of the Family Health Strategy in Northeastern Brazil
}

Roseléia Carneiro dos Santos (https://orcid.org/0000-0003-4243-3616) ${ }^{1}$

Maria Lúcia Magalhães Bosi (http://orcid.org/0000-0001-9742-9230) ${ }^{2}$

${ }^{1}$ Centro de Atencão Psicossocial Geral Prof. Frota Pinto, Secretaria Municipal de Saúde de Fortaleza. R. Francisco Pedro 1269, Rodolfo Teófilo. 60430-357 Fortaleza CE Brasil.rosesantos@ufc.br ${ }^{2}$ Laboratório de Avaliação e Pesquisa Qualitativa em Saúde, Faculdade de Medicina, Universidade Federal do Ceará. Fortaleza CE Brasil.

\begin{abstract}
The Family Health Strategy (FHS) of the Unified Health System (SUS) is the revised model that governs health care and the work processes adopted in Brazil. This article analyzes the perceptions of FHS professionals regarding mental health and the care provided in a health center in a Basic Care Unit in the Brazilian Northeast. It involved qualitative research aligned with a critical interpretative approach conducted through interviews, straightforward observation and documentary analysis that led to a series of considerations organized into two main groups: a) "Mental Health" from the perspective of professionals of the FHS; and b) Care in "Mental Health" in the context of practices of primary care. The results of the study reveal conceptions about mental health limited to a view aligned with a project of institutionalization and medicalization. With respect to the dimension of care, gaps are revealed in relation to shared experiences in mental health, through the incipient partnership between professionals of the FHS and the Nucleus of Support in Family Health (NSFH). The challenge remains to reconstruct a vision aligned with the precepts of Brazilian psychiatric reform, teamwork and the creation of spaces that enable discussion and agreements in the daily routine of the FHS.
\end{abstract}

Key words Public health policies, Family Health Strategy, Mental health, Qualitative research
Resumo O Sistema Único de Saúde (SUS) tem na Estratégia Saúde da Família (ESF) o modelo reorientador da atenção e do processo de trabalho. $O$ artigo analisa concepções de profissionais da ESF relativas à saúde mental e à produção do cuidado em uma Unidade Básica de Saúde, no Nordeste brasileiro. Trata-se de uma pesquisa qualitativa, alinhada à vertente crítico interpretativa, empregando entrevistas, observação livre e análise documental gerando uma rede de significados organizada em dois eixos: a) "Saúde Mental" na perspectiva dos profissionais da Estratégia Saúde da Família e b) O cuidado em "Saúde Mental": a práxis no contexto da atenção básica. Apesar do potencial dos dispositivos, os resultados do estudo evidenciam concepções acerca da saúde mental circunscritas a uma visão congruente com um projeto de institucionalização e medicalização. No que concerne à dimensão do cuidado, revelam-se lacunas relativas às experiências em saúde mental compartilhadas, através de incipiente parceria entre profissionais da ESF e NASF. Persiste o desafio de reconstruir uma visão alinhada aos preceitos da reforma psiquiátrica brasileira e, na materialidade do trabalho em equipe, criação de espaços que possibilitem no cotidiano da ESF discussões, planejamentos e pactuações.

Palavras-chave Políticas Públicas de Saúde, Estratégia Saúde da Família, Saúde Mental, Pesquisa Qualitativa 


\section{Introdução}

Desde a sua criação, no final dos anos 1980, o Sistema Único de Saúde (SUS) vem passando por inúmeras transformações, com vistas a se materializar como uma política pública democrática e universal ${ }^{1}$. Para tanto, efetivou uma série de reformulações nas políticas de saúde que culminaram em novas propostas de composição de equipes, reorganização do processo de trabalho e até mesmo criação de políticas e programas inéditos, atribuindo-se destaque à Estratégia Saúde da Família (ESF) como modelo reorientador da atenção e do processo de trabalho das equipes das unidades básicas de saúde visando expandir, qualificar e consolidar os cuidados primários em saúde ${ }^{2,3}$. Reafirma-se o papel central da atenção básica como coordenadora do cuidado e ordenadora da rede ${ }^{2,3}$. Além disso, a literatura é rica em evidências de que sistemas de saúde sob essa égide tornam-se mais efetivos, mais satisfatórios à população, mais equitativos e menos onerosos ${ }^{4}$.

No cenário brasileiro, o conjunto normativo que abarca os serviços vinculados à Atenção Básica encontra-se sistematizado na Política Nacional de Atenção Básica (PNAB), recentemente reformulada ${ }^{3}$, e conta com o arranjo basilar de uma equipe denominada Equipe de Saúde da Família (eSF), composta, em seu formato mínimo, por médicos(as), enfermeiros(as), agentes comunitários de saúde (ACS) e técnicos de enfermagem. Nos últimos anos, houve grande expansão da ESF no Brasil, com nítida representatividade na região nordeste ${ }^{5}$. Todavia se reconhece a persistência de inúmeras barreiras organizacionais que dificultam a efetivação do acesso, integração e resolubilidade na ESF5.

Frente à necessidade de incremento das práticas de cuidado sob responsabilidade das eSF - as quais tem se revelado, cada vez mais, complexas e desafiadoras no cotidiano dos serviços básicos ${ }^{6,7}$ - o Ministério da Saúde (MS) criou, mediante Portaria GM no 154/2008, o Núcleo de Apoio à Saúde da Família (NASF) com vistas a ampliar a abrangência e o escopo das ações da atenção básica $^{8}$. Conferimos destaque a esse dispositivo, por se caracterizar não somente como inovação, mas por seu lugar na ampliação das práticas em Saúde Mental, foco desta análise.

Os NASF's são formados por profissionais de diferentes áreas de conhecimento, incluindo a saúde mental, que devem atuar de forma integrada à rede de serviços de saúde, tomando como ponto de partida as demandas identificadas no trabalho conjunto com as eSF, tornando-as mais potentes e resolutivas ${ }^{8,9}$. Cabe salientar que, em 2017, a partir da revisão das diretrizes para a organização da atenção básica ${ }^{3}$, o NASF passou a ser chamado de Núcleo Ampliado de Saúde da Família, visando assim aproximá-lo de uma vertente mais assistencialista, alinhando-se ao que Morosini et al. ${ }^{10}$ denomina racionalidade neoliberal, para exprimir as consequências nefastas da Emenda Constitucional no 95/2016, que congelou por 20 anos a destinação de recursos públicos destinados à seguridade social. A despeito dessa mudança, optamos, em permanecer utilizando neste artigo a nomenclatura NASF atrelada à noção de "apoio", tanto por esta ser a mais difundida na literatura, como por considerarmos mais apropriada ao ideário do SUS segundo o qual se estruturou sua proposta de trabalho, fundamentada no arranjo do apoio matricial ${ }^{11}$.

Considerando o conjunto de reformulações da política de saúde brasileira e a escassez de estudos sobre o tema, no presente artigo, analisaremos concepções de profissionais da Estratégia Saúde da Família relativas à saúde mental e à produção do cuidado nesse âmbito, em uma Unidade de Saúde no Nordeste brasileiro, explorando ainda, experiências compartilhadas e perspectivas quanto a contribuições do NASF no cotidiano do serviço investigado.

\section{Método}

Dada a natureza do objeto investigado, o estudo fundamentou-se nos pressupostos da abordagem qualitativa de pesquisa em saúde ${ }^{12,13}$ conjugada à avaliação qualitativa de programas de saúde ${ }^{14}$. A pesquisa se afilia ao paradigma interpretativo e, em seu interior, à tradição crítico interpretativa, ancorada nos preceitos da Hermenêutica ${ }^{15}$, como base epistemológica, na qual a "compreensão" é a via de aproximação dos fenômenos sob estudo, sendo a intersubjetividade vinculada à materialidade da existência.

O cenário da pesquisa é uma unidade básica de saúde localizada na cidade de Fortaleza, município de grande porte do Nordeste brasileiro, tendo sido os participantes selecionados mediante a estratégia de amostragem intencional ${ }^{16}$. Para seleção da unidade, consultamos a opinião de diversos informantes chave acerca de um cenário onde práticas em saúde mental na atenção básica vinham sendo desenvolvidas, em parceria com o NASF, dentre eles: gestores ligados à atenção básica e NASF, gestores da área técnica de saúde mental, coordenações distritais de saúde mental e do 
NASF, bem como, a opinião de alguns egressos da Residência Multiprofissional em Saúde da Família e Comunidade e mestrandos com pesquisas em áreas afins.

Para realização do trabalho de campo, empregamos: entrevistas dialógicas, observação livre e análise documental. Respeitando-se as categorias profissionais existentes na composição das equipes da SF atuantes na unidade de saúde, realizamos um total de 12 entrevistas englobando os seguintes participantes: 8 (oito) agentes comunitários de saúde, 2 (duas) médicas, 1 (uma) enfermeira e 1 (uma) técnica de enfermagem, caracterizados no Quadro 1.

Para a apreensão dos depoimentos dos participantes da pesquisa foram realizadas entrevistas individuais, mediante as quais, de forma não diretiva e dialógica, se explorou a seguinte questão norteadora, desdobrando-a consoante o diálogo com os participantes: "Como vem se dando, em sua equipe, as experiências em saúde mental desenvolvidas com os profissionais do NASF?". Os depoimentos dos entrevistados foram gravados, após consentimento e devida assinatura do Termo de Consentimento Livre e Esclarecido (TCLE), tendo sido o estudo aprovado pelo Comitê de Ética em Pesquisa da Universidade Federal do Ceará (UFC).

As observações livres visaram favorecer o entendimento de rotinas e a dinâmica de interação entre os profissionais do serviço, possibilitandonos ainda o registro de insights, cenas e episódios no decorrer do trabalho de campo, relevantes ao exercício de reflexividade das pesquisadoras, mas sem a pretensão de comporem o corpus discursivo, haja vista seu caráter assistemático.
A utilização da técnica de análise documental consistiu na leitura e sistematização de diversas fontes relacionadas à pesquisa, versando sobre princípios normativos, modelo estrutural que enriqueceram dimensões do funcionamento da saúde mental na atenção básica. De posse do material empírico advindo das entrevistas, passamos ao processamento e posterior exercício interpretativo, ancorado, como já aludido, na Hermenêutica crítica ${ }^{15}$ como tradição no paradigma interpretativo, tendo sido a análise orientada por categorias analíticas vinculadas ao arcabouço teórico da saúde coletiva e das ciências humanas e sociais em saúde, sendo a rede de significados do estudo, constituída pelos seguintes temas centrais: a) Saúde mental na perspectiva dos profissionais da Estratégia Saúde da Família e b) O cuidado em "Saúde Mental": a práxis no contexto da atenção básica.

\section{Saúde mental na perspectiva dos profissionais da Estratégia Saúde da Família}

Os participantes do estudo, por unanimidade, abordaram o tema aludindo à oferta de assistência às pessoas com diagnósticos psiquiátricos já consolidados e/ou com sinais e sintomas característicos de entidades nosológicas ou transtornos mentais específicos ${ }^{17}$ de notória identificação:

Tenho o caso de uma paciente, idosa, ...procurou o posto dizendo que estava nascendo cabelo nas mãos. Ela ficava todo tempo puxando porque ela disse que nascia cabelo. [...] Ela disse que já não dormia por causa dessa "ferviação"... ela chamava de "ferviação" dos cabelos na mão. (Profissional 01).

Quadro 1. Caracterização dos profissionais de saúde entrevistados, segundo ocupação, sexo, formação, idade e tempo de atuação na ESF.

\begin{tabular}{|l|l|l|l|c|c|}
\hline Cód. Profissional & Ocupação & Sexo & Formação & Idade & Tempo na ESF \\
\hline 01 & Médico & Feminino & Pós-graduada & 63 anos & 6 anos \\
\hline 02 & Médico & Feminino & Pós-graduada & 35 anos & 6 anos \\
\hline 03 & Enferm. & Feminino & Pós-graduada & 32 anos & 6 anos \\
\hline 04 & ACS & Feminino & Ens. Méd. Comp. & 38 anos & 1,5 anos \\
\hline 05 & ACS & Feminino & Ens. Méd. Comp. & 35 anos & 5 anos \\
\hline 06 & ACS & Feminino & Ens. Méd. Comp. & 36 anos & 2 anos \\
\hline 07 & ACS & Masculino & Ens. Méd. Comp. & 37 anos & 2 anos \\
\hline 08 & ACS & Masculino & Ens. Méd. Comp. & 29 anos & 3,5 anos \\
\hline 09 & ACS & Feminino & Ensino Técnico & 31 anos & 1,6 anos \\
\hline 10 & ACS & Feminino & Sup. Incomp. & 30 anos & 3 anos \\
\hline 11 & ACS & Feminino & Ens. Méd. Comp. & 38 anos & 1,6 anos \\
\hline 12 & ACS & Feminino & Ensino Técnico & 34 anos & 2,7 anos \\
\hline
\end{tabular}

Fonte: elaboração própria. 
Ele [usuário] fala coisa com coisa, inclusive ele piorou. [...] ele se veste de mulher, entendeu?! Anda com o cachorro dele na área lá, cachorro sujo e ele também pelas ruas... (Profissional 07).

A despeito de a pergunta disparadora ter utilizado, claramente, o termo "saúde" mental, emergiu espontaneamente, entre os profissionais entrevistados, narrativas a respeito do fenômeno em sua vertente oposta, ou seja, "doença" mental $^{18}$. Constata-se, portanto, na unidade de saúde investigada, o predomínio de práticas alinhadas ao paradigma biomédico e ao modelo asilar ${ }^{19}$.

Salientamos que, ao representarem a "saúde mental" ancorada no paradigma psiquiátrico clássico, os profissionais acabam por reduzir as experiências dessa natureza associando-as ao que Pessoti $^{20}$ nomeia "perda das capacidades racionais e/ou falência do controle voluntário sobre as paixões", atribuindo uma condição irreversível aos quadros de transtorno mental, que passariam a necessitar de medicação para o seu controle e estabilização ${ }^{21}$.

Tal achado mostra-se relevante na medida em que, conforme nos aponta Amarante ${ }^{22}$, no Brasil e em vários outros países, os ideais e diretrizes do movimento de Reforma Psiquiátrica (RP), vem gerando, nos últimos anos, transformações no modelo assistencial destinado às pessoas com transtorno mental, contestando a psiquiatria clássica, reformulando seu objeto e linhas de ação. Tal movimento busca legitimar a "saúde mental" como um campo de produção de conhecimentos e práticas que, para o Ministério da Saúde ${ }^{23}$, "mais do que diagnosticar e tratar, liga-se à prevenção e promoção de saúde", além de preocupar-se com a reabilitação e reintegração do paciente em seu contexto social" ${ }^{23}$ (p.14).

Para tanto, o movimento de Reforma Psiquiátrica Brasileira (RPB), prevê a criação e a articulação de diversos dispositivos sociais presentes nos territórios, de modo a promover alternativas à internação e ao confinamento das pessoas com transtorno mental, lançando mão de novas possibilidades de cuidar ${ }^{6}$, sob a égide do que Costa -Rosa et al. ${ }^{24}$ demarcam como modelo de atenção "Psicossocial". Segundo estes autores ${ }^{24}$, a abordagem psicossocial serve para designar o conjunto de práticas reformadoras referentes às "transformações nas concepções de 'objeto', nos modos de conceber e estruturar a instituição como dispositivo, e, sobretudo, na forma de conceber e estruturar as relações terapêuticas, que têm, por sua vez, implicações éticas radicalmente distintas das práticas asilares"24(p.19). Trata-se, portanto, de uma desconstrução e transformação do mo- delo tradicional da psiquiatria clássica que como podemos verificar, ainda se mostra presente, no plano das concepções, no espaço analisado.

Tais concepções, longe de serem idealidades, se desdobram no foco atribuído pelos entrevistados às manifestações de "transtornos graves e persistentes” como critério de delimitação dos casos considerados como de Saúde Mental vigentes em suas equipes, conflitando com o ideário do SUS e das Reformas Sanitária e Psiquiátrica Brasileiras, mesmo decorridos anos de sua instauração:

[...] Ela fica trancada, a mãe separou, a casa é aqui [faz gesto com mão]. Só que quando ela está medicada, a mãe, à tarde, solta para ela dar um volta na rua, ela não conversa nada que faça sentido. (Profissional 05).

Grave é aquela pessoa que precisa de uma internação... Uma pessoa que agride, uma pessoa que não dá... não tem nem como você conversar. (Profissional 11).

Ao conceber a pessoa com transtorno mental como a que "precisa de internação", "que agride" e "não tem nem como você conversar", os entrevistados acabam por exprimir um entendimento restrito e pouco fundamentado, convergindo para visões estereotipadas e congruentes com o modelo asilar. Desse modo, deixam de contemplar uma gama de experiências relativas ao âmbito da saúde mental, possivelmente existentes em seus territórios, mas não vislumbradas em virtude desse olhar restrito.

Cabe salientar que esta é uma realidade vigente em vários outros estudos realizados no cenário da atenção básica no Brasil ${ }^{25,26}$, o que pode estar associado ao desconhecimento por parte de alguns profissionais dos pressupostos da Reforma Psiquiátrica e da Política de Saúde Mental em curso no Brasil, bem como, à permanência de uma visão estigmatizada acerca da pessoa com transtorno mental, segundo Maciel et al. ${ }^{27}$, perpetuada ao longo da História, e não desconstruída em muitos espaços de formação profissional, onde já seria esperada uma superação.

O profissional 01, por exemplo, exprime sua visão acerca da pessoa com transtorno mental da seguinte forma: "a posição de uma pessoa que não é boa da cabeça dentro de sua casa, deve ser uma condição respeitosa com ela, porque ela é limitada". Consoante esta visão, o profissional 07 considera não ser possível uma assistência às pessoas com transtorno mental nas unidades de saúde, justificando a sua opinião da seguinte forma: "Uma pessoa dessa, sozinha, não tem condições de vir, e se ela vier, não vai entender o que está sendo dito, né?! Não tem sentido isso". 
Buscando aprofundar o modelo de assistência que este último profissional acredita ser necessário às pessoas com transtorno mental, já que a atenção básica não é em sua visão um local de produção de cuidado em saúde mental, assim prossegue o seu raciocínio:

Eu acho que o governo deveria abrir um hospital mental...para pegar pessoas carentes, que tem muita gente carente que tem transtorno mental. Não tem, não tem esse equipamento na saúde pública, pelo menos para o meu conhecimento. $O$ governo, a prefeitura ou o governo do Estado, o governo federal abrir uma casa só para quem tem problema mental, né?! E realmente com muitas vagas, né?! (Profissional 07).

A fala acima advogando por um modelo asilar surpreende em se tratando de um profissional atuante em um dispositivo resultante da Reforma Sanitária Brasileira ${ }^{1}$; mais que isso, reforça um sistema de tratamento fundado em práticas centradas sobretudo na internação e na "medicalização" próprias do modelo asilar ${ }^{19}$, indicando um confronto incisivo com os pressupostos e princípios ético políticos da Reforma Psiquiátrica e da Política Nacional de Saúde Mental vigentes.

Entre os participantes pertencentes à categoria de agentes comunitários de saúde, verificaram-se lacunas ainda maiores no eixo formativo, bem como, a permanência de uma visão depreciativa e estigmatizante da pessoa com transtorno mental:

Porque eu vou ser sincera... eu tenho medo! O que falar? O que fazer? Como reagir? (Profissional 05).

No começo, eu fiquei até um pouco assustada, porque eu fiquei com medo de assim, [risos] de alguma violência, né ?... porque ele já foi violento até com a própria família. (Profissional 10).

Tal achado reitera-se em outros estudos em municípios brasileiros ${ }^{28,29}$, compondo um aspecto central da discussão referente ao cuidado em saúde mental na atenção básica e que sinaliza a necessidade de um reordenamento das políticas e programas com vistas ao fortalecimento de propostas de educação em serviço/educação permanente que contemplem o tema, a partir de eixos fundamentais do trabalho no SUS, que Ceccim e Feuerwerker ${ }^{30}$ consideram relevantes como aspectos da valorização do ensino, gestão, atenção e controle social.

Para tanto, conferimos destaque ao papel do NASF no desenvolvimento de ações de educação permanente junto às eSF vinculadas ${ }^{31}$. Este aspecto já se encontra garantido no âmbito normativo, através do incentivo às "ações que visem à difusão de uma cultura solidária e inclusiva, diminuindo o preconceito e segregação com a loucura"'(p.42), cabendo às equipes NASF se atentarem para a potência do apoio a ele associado, aproximando assim a sua práxis, de conteúdos e discussões vigentes em manuais e regulamentos, de forma a torná-los processos vivos na materialidade da produção do cuidado ofertado no cotidiano dos serviços.

Por fim, em um momento em que a humanização da assistência vem sendo uma "peça" fundamental para a mudança do paradigma ${ }^{5}$, a criação de espaços de formação, bem como de apoio e suporte para os profissionais da ESF, desponta como potente ferramenta em favor de uma maior aproximação entre as equipes de saúde e os usuários e familiares convivendo com a problemática "Saúde Mental"31. Dessa forma, partimos da defesa da valorização de espaços coletivos/ dialógicos no âmbito da saúde, nos quais os diversos segmentos e dispositivos sociais possam se encontrar, contribuindo assim para a formação de uma clínica de qualidade, mais comprometida e participativa ${ }^{7}$.

\section{O cuidado em "saúde mental": a práxis no contexto da atenção básica}

A análise dos resultados demonstrou uma incipiente prática voltada à produção do cuidado em saúde mental no cenário da atenção básica investigado. Dentre as poucas experiências em curso na equipe, foi possível notar frágil engajamento por parte da eSF pesquisada em relação à temática, bem como, uma cisão na natureza das ações desenvolvidas por profissionais de nível superior e ACS's, o que denota uma desarticulação das ações, primeiramente, no interior da própria eSF.

Os depoimentos dos profissionais de nível superior (médicos e enfermeiros) versaram sobre experiências em saúde mental voltadas ao contexto clínico assistencial, destacando-se dentre elas a realização de consultas para renovação de receituário e/ou encaminhamento de pacientes aos profissionais do NASF e serviços especializados. Cabe salientar que tais ações ocorreram, grande parte do tempo, no lócus da unidade básica, apresentando uma tendência, por parte dos profissionais de nível superior, à produção do cuidado em saúde mental através de ações intramuros ${ }^{32}$ :

As pessoas tinham seus pacientes e precisavam da receita, e eu dizia assim: "Bom, se tiver uma receita eu atendo a receita, mais não... Só isso!” [...] (Profissional 01). 
Eu acho que a gente não tem uma assistência boa para o pessoal da saúde mental, nem eu, nem a Dra. X, nem a minha equipe. [...] Às vezes os agentes de saúde me trazem uma ou duas pessoas... O que é que a gente faz? Encaminha para Dra. Y, que não é da equipe, porém, ela tem uma aproximação maior com a temática... Pronto, é assim que funciona. (Profissional 03).

Já entre os entrevistados pertencentes à categoria de ACS's, foi possível identificar, com maior frequência, experiências no território, estando entre as principais as visitas domiciliares e/ou contatos diários com usuários pertencentes à sua rede social, uma vez que compartilham o dia a dia da comunidade ${ }^{6}$. Nessa direção, observamos que os agentes comunitários de saúde, por estarem inseridos no mesmo território existencial das famílias adscritas em sua equipe de atuação, lidam de modo mais contínuo com a pessoa com transtorno mental, revelando-se, portanto, um importante ator na produção do cuidado em saúde mental na atenção básica:

[...] é um senhor já dos seus quarenta e cinco, cinquenta anos, a família abandonou e ele vive perambulando pela rua, mora na minha área, entendeu?! É uma pessoa difícil de lidar, até mesmo porque ele, às vezes, se torna agressivo, com palavras, né, não com gestos. Aí quando eu encontro ele na área, eu falo: "Seu F., vá tomar um banho, vá para casa!'.(Profissional 07).

Às vezes eu me sinto uma inútil. Eu não sei o que fazer. Um dia eu passei lá e estava o maior escândalo, o menino estava tendo uma crise e você fica assim... [...] sem saber o que fazer, sem saber como ajudar aquela família. Quando você vai aos cursos você faz até umas encenações que dá tudo certo, mas quando você vai para a prática você fica tão amarrada, sabe?! (Profissional 04).

Sobre o contato mais intenso dos ACS's com os casos de transtorno mental da área, Nunes et al. ${ }^{26}$ chamam a atenção para o fato de tal proximidade nem sempre vir acompanhada de conhecimentos e habilidades suficientes para o trato com as problemáticas de saúde mental, o que torna frequentes os sentimentos de impotência e frustração entre os trabalhadores, ao que se soma a "angústia provocada ao defrontar-se com situações humana e afetivamente exigentes"26(p.2381).

No dia que eu tinha que fazer a visita, o quartinho da D... ela tinha defecado tudo, estava um mal cheiro, era urina e o prato dela no chão. Aí, quer dizer, as condições que a $D$ estava vivendo... [Pausa em decorrência da expressão de emoção] (Profissional 05).

Os relatos, juntamente com a literatura ${ }^{32-34}$ sugerem premência na criação de espaços per- manentes de formação profissional, principalmente aqueles "onde vários profissionais têm a oportunidade de aprender na prática cotidiana do atendimento das demandas de saúde mental"'. Atesta-se, ante essa possibilidade, o importante papel do NASF como articulador/mediador de ações relativas ao campo da saúde mental, à medida em que uma de suas atribuições é elaborar projetos terapêuticos singulares e atendimentos compartilhados, junto aos profissionais da ESF, priorizando a avaliação de riscos e manejo dos casos, primordialmente, aqueles em que a eSF tem apresentado dificuldades?. Entretanto, tais iniciativas não foram vislumbradas, no decorrer da pesquisa, o que nos faz considerar que o apoio ofertado pelo NASF às eSF, carece de melhor apropriação por parte das equipes, seja pelo distanciamento, ausência de programação ou de espaços de compartilhamentos.

Desse modo, privilegiar estratégias construídas de forma interdisciplinar, integrando eSF e NASF na busca por soluções de problemas desafiantes e reais parecem despontar como formas possíveis de se abordar a produção do cuidado em saúde mental na atenção básica. Além disso, propiciar espaços de escuta e acolhimento das angústias e dificuldades da eSF relativas ao cotidiano de trabalho com pessoas com transtorno mental podem ser favoráveis a uma assistência em saúde mental mais humanizada e menos geradora de sofrimento para os profissionais que lidam no dia a dia com a temática.

Dentre o conjunto limitado de práticas relativas ao âmbito da saúde mental desenvolvidas em parceria com o NASF, os entrevistados de nível superior (médico e enfermeiro), mencionaram as ações de encaminhamento de pacientes para avaliação por parte de um profissional do NASF e a participação conjunta (de eSF e NASF) na reunião do Matriciamento:

Eu tenho a minha limitação enquanto médica, por exemplo, em fazer uma avaliação psicológica, aquela avaliação diagnóstica mesmo. O NASF entra aí com a visão do psicólogo, com a visão do assistente social, que a gente não tem, não adianta. (Profissional 02).

O NASF... ele atua bem com essa história do matriciamento, principalmente tem a assistente social, a G e a S, psicóloga, que ela é bem atuante. E elas mesmas levam o caso. Às vezes, os próprios agentes de saúde levam para elas e elas mesmas levam o caso para dentro do matriciamento... (Profissional 03).

Já entre os agentes comunitários de saúde, foram apresentadas as seguintes práticas desenvolvidas a partir do contato com o NASF: levan- 
tamento dos casos de transtornos mental de suas áreas de atuação e visitas domiciliares:

Eu vou dar um exemplo: Um paciente nosso, que a gente foi visitar, e quando chegou lá ele super depressivo, bem ruim mesmo. [...] Elas [profissionais do NASF] muitas vezes vão com a gente paras as visitas... (Profissional 05).

Roese e Lopes ${ }^{35}$ consideram a visita domiciliar do ACS um instrumento potencializador no que nomeiam "coleta de dados" em pesquisa e nas ações de vigilância em saúde, pelo fato de conhecerem cada família, e pelo contato mantido durante anos. Esta perspectiva poderia servir, à primeira vista, para corroborar a importância de atividades tais como a do levantamento de demandas de saúde mental ou casos reconhecidos como transtorno mental, proposta pelo NASF aos ACS's. Contudo, assinalamos que, o fato de a atividade não ter gerado produtos, resumindo-se apenas à coleta de informações, pode ter contribuído para que alguns ACS's, mesmo tendo executado a tarefa (3 de um total de 8 ), não a reconhecessem diretamente como uma ação em parceria com o NASF. Ligada a esta questão, observamos ainda, nas falas dos profissionais, o desconhecimento da finalidade de tal ação, o que sinaliza um caráter verticalizado, distanciando-a de uma proposta efetiva de trabalho em equipe, na qual o diálogo abrange todos os atores envolvidos, legitimando discussões, planejamentos, pactuações e avaliações dos trabalhos conjun$\operatorname{tos}^{34,36}$.

Sobre tal aspecto, Campos ${ }^{7}$ chama a atenção para o fato de a organização parcelar do trabalho fixar os trabalhadores em uma determinada etapa do projeto terapêutico e da produção do cuidado, comprometendo assim, a visão de totalidade do processo. Em suas palavras, "a superespecialização, o trabalho fracionado, fazem com que o profissional de saúde se aliene do próprio objeto de trabalho"7 (p.572), dificultando assim, a operacionalização de ações integrais que privilegiem a concretude da vida dos sujeitos. Como não há interação em todo o processo de cuidado, possivelmente não haverá compromisso com o resultado do mesmo, confluindo em processos de trabalho compartimentalizados, com intervenções/ações fragmentadas entre os diversos profissionais.

Nessa direção, o caráter inacabado da atividade de levantamento dos casos relativos à saúde mental proposta aos ACS's desvela o quanto a produção do cuidado em saúde depende do grau de interação entre as várias identidades profissionais, primordialmente no âmbito da ESF, onde o trabalho em equipe é considerado ferramenta primordial no desenvolvimento das ações ${ }^{7,10}$.

Através do estudo pudemos verificar que o conjunto de atividades em saúde mental desenvolvidas em parceria com o NASF, não faz parte de um universo comum, evidenciando, mais uma vez, um alto nível de compartimentalização do cuidar, expresso em depoimentos como: "eles [profissionais do NASF] participam bem do matriciamento", “a psicóloga ficou fazendo visita e depois encaminharam". Ressalta-se que a produção do cuidado em saúde mental na atenção básica, prevê o exercício de práticas conjuntas, mediante integração NASF - eSF, com vista à superação da lógica de referência e contrarreferência, o que não se mostrou presente no cenário investigado. Desse modo, não foram observados espaços de compartilhamentos e trocas que pudessem sugerir a materialidade da coresponsabilidade pela produção do cuidado em saúde mental entre eSF e NASF.

Por essa razão, apesar de o NASF estar vinculado à equipe SF havia aproximadamente 2 (dois) anos, consideramos a relação entre as equipes como estando em um momento de aproximação/apropriação, tendo em vista que o NASF, à época do estudo, não desenvolvia nenhuma ação integrada mais efetiva.

No que diz respeito à menção do Apoio Matricial como uma atividade em conjunto realizada por equipe SF e NASF, presente no relato do profissional 03, observamos outro elemento exemplificador das fragilidades vivenciadas pelas equipes (SF e NASF) no que tange à produção do cuidado em saúde mental na atenção básica. Teoricamente, o apoio matricial é entendido como uma retaguarda ou apoio especializado ofertado à equipes de referências (essas sim responsáveis pela atenção longitudinal de aspectos clínicos e sanitários existentes em sua realidade $)^{7,37}$. O apoio neste caso poderia ser tanto de retaguarda assistencial como de suporte técnico-pedagógico, objetivando sempre, de acordo com Campos ${ }^{7}$ "construir e ativar espaço para comunicação ativa e para o compartilhamento de conhecimento entre profissionais de referência e apoiado$\operatorname{res}^{\prime 7}(\mathrm{p} .401)$.

$\mathrm{Na}$ realidade da unidade básica de saúde investigada, constatamos que mesmo reconhecendo a contribuição do NASF às ações de Apoio Matricial, as funções delegadas aos seus profissionais, mostraram-se, muitas vezes, atreladas ao cumprimento de papéis burocráticos: realização de avaliação dos casos encaminhados pelos profissionais da equipe SF, para, finalmente, orga- 
nizar os nomes daqueles que, prioritariamente, seriam levados para discussão no matriciamento, bem como, marcação do dia do encontro e reservas de sala e equipamentos necessários ao bom funcionamento da reunião mediada pelo Centro de Atenção Psicossocial (CAPS).

Além disso, o fato de não ter ocorrido nenhuma reunião de Apoio Matricial durante o período do trabalho de campo do estudo, ou seja, durante 3 meses consecutivos, indica fragilidades no desenvolvimento da proposta, que à época do estudo, enfrentava principalmente obstáculos de ordem estrutural (como não disponibilidade de carro e de profissionais para a execução da tarefa) não podendo, no referido cenário, demonstrar sua efetiva contribuição como dispositivo propiciador de oferta de cuidado em saúde mental na atenção básica.

Em relação aos obstáculos impostos à prática do matriciamento, Dimenstein et al. ${ }^{38}$, constataram em estudo também realizado no Nordeste brasileiro que o apoio matricial não foi assimilado de modo satisfatório pelos profissionais de SF, prevalecendo um cenário de incertezas e expectativas equivocadas por parte de alguns profissionais. De modo similar, encontramos tais características no presente estudo, além de identificarmos práticas de matriciamento compartimentalizadas e fragmentadas, muitas delas ancoradas na lógica do encaminhamento e da desresponsabilização pela continuidade do cuidado ${ }^{36,38}$, corroborando a necessária e urgente implementação de melhorias no cuidado em saúde mental, tanto por parte da equipe SF como das possíveis contribuições do NASF a este cenário.

A presença de entraves de diversas naturezas na operacionalização das ações relativas ao campo da saúde mental, não desmerecem o caráter estratégico e inovador do dispositivo NASF e tampouco as potencilidades do cuidado em Saúde Mental na Atenção Básica. Tais obstáculos são parte do complexo processo de construção das políticas de atenção básica e saúde mental brasileiras - permeada de contradições e dificuldades, vivendo hoje retrocessos - outras tantas vinculadas ao saber/fazer dos profissionais da equipe SF da família, que se devidamente reconhecidas podem eliciar percursos e experiências exitosas em saúde mental ${ }^{39,40}$.

\section{Considerações finais}

Apesar de a equipe SF investigada possuir cerca de seis anos de atuação, dois deles contando com a presença do NASF, observou-se ainda um momento de apropriação acerca das propostas e paradigmas atuais refentes à produção do cuidado em saúde mental, constatado por meio de um processo incipiente de experiências em saúde mental realizadas em parceria pelos profissionais das equipes Saúde da Família e NASF.

Concluímos que o NASF, idealizado como dispositivo para potencializar as ações das equipes de SF, se defronta com inúmeros desafios e dificuldades vigentes na atenção básica, passando a lidar com realidades marcada por obstáculos estruturais, de gestão, além daqueles relativos à organização dos próprios processos de trabalho, do desenvolvimento das ações junto a equipe SF e/ou com demais equipes dos dispositivos da rede com quem precisa, muitas vezes, se comunicar.

Aliado a isso, no município onde se desenvolveu o estudo, as equipes NASF encontravam-se, submetidas a condições precárias de vínculos trabalhistas, bem como, a carência de estratégias de formação, uma vez que a forma de contratação utilizada pelas diferentes gestões, desde o ano de 2009, consistiu na realização de seleção - com duração de no máximo dois anos - inexistindo concurso público com vistas a contemplar essa área de atuação.

Nessa direção, a alta rotatividade de profissionais do NASF, bem como, o pouco tempo de atuação junto às equipes de SF são dificultadores do processo de acúmulo teórico e prático, despontando como um importante empecilho à materialização de ações integrais, coletivas e bem fundamentadas por parte dos profissionais da ESF no campo da saúde mental.

Dentre as experiências inaugurais em curso na equipe, chamou-nos a atenção o fato de muitas atividades mencionadas reforçarem a lógica fragmentária dos processos de cuidado, tanto entre os membros da equipe SF, como entre esta e a equipe NASF, não sendo vislumbrados percursos de atuações conjuntas, integradas e intersetoriais entre NASF e equipe SF e demais serviços, principalmente no que tange a uma concepção ampliada, integral e compartilhada do processo saúde doença, defendida pelo SUS.

Frente a isso, reconhecemos a Atenção Básica e o trabalho das equipes de Saúde da Família e a parceria com o NASF espaços fundamentais na produção do cuidado em Saúde Mental, numa perspectiva de desinstitucionalização. $\mathrm{O}$ desafio continua sendo a superação de problemas estruturais, bem como, o fortalecimento de iniciativas de formação profissional, nas quais sejam possíveis a construção de diálogos coletivos propulsores de discussões, planejamentos, pactuações e avaliações dos processos de trabalhos conjuntos. 


\section{Colaboradores}

Ambas as autoras participaram de todas as etapas do estudo, desde à concepção à revisão final da publicação.

\section{Referências}

1. Brasil. Constituição da República Federativa do Brasil de 1988. Diário Oficial da União 1988; 5 out.

2. Brasil. Ministério da Saúde (MS). Secretaria de Atenção à Saúde. Departamento de Atenção Básica. Política Nacional de Atenção Básica. Brasília: MS; 2012

3. Brasil. Ministério da Saúde (MS). Portaria n 2.436 , de 21 de setembro de 2017. Aprova a Política Nacional de Atenção Básica, estabelecendo a revisão de diretrizes para a organização da atenção básica. Diário Oficial da União 2017; 22 set.

4. Starfield B. Atenção Primária: equilíbrio entre necessidades de saúde, serviços e tecnologia. Brasília: UNESCO, MS; 2002.

5. Campos GWS, Pereira Júnior N. A Atenção Primária e o Programa Mais Médicos do Sistema Único de Saúde: conquistas e limites. Cien Saúde Colet 2016; 21(9):2655-2663.

6. Lancetti A. Clínica peripatética. São Paulo: Editora Hucitec; 2006.

7. Campos CEA. O desafio da integralidade segundo as perspectivas da vigilância da saúde e da saúde da família. Cien Saude Colet 2003; 8(2):569-584.

8. Brasil. Ministério da Saúde (MS). Portaria GM no 154 , de 24 de janeiro de 2008. Cria os Núcleos de Apoio à Saúde da Família - NASF. Diário Oficial da União; 2008.

9. Brasil. Ministério da Saúde (MS). Secretaria de Atenção à Saúde. Departamento de Atenção básica. Diretrizes do NASF: Núcleo de Apoio à Saúde da Família. Brasília: MS; 2010.

10. Morosini MVGC, Fonseca AF, Lima LD. Política Nacional de Atenção Básica 2017: retrocessos e riscos para o Sistema Único de Saúde. Saude Debate 2018; 42(116):11-24.

11. Campos GWS, Domitti AC. Apoio matricial e equipe de referência: uma metodologia para gestão do trabalho interdisciplinar em saúde. Cad Saude Publica 2007; 23(2):399-407.

12. Minayo MCS. O desafio do conhecimento: pesquisa qualitativa em saúde. 12a ed. São Paulo: Hucitec; 2010.

13. Bosi MLM, Mercado FJ. Pesquisa qualitativa de serviços de saúde. 2a ed. Petropólis: Vozes; 2007.

14. Bosi MLM, Mercado FJ. Avaliação qualitativa de programas de saúde: enfoques emergentes. Petropólis: Vozes; 2006.

15. Gadamer HG. Verdade e Método I: traços fundamentais de uma hermenêutica filosófica. 10a ed. Petrópolis: Vozes; 2008.

16. Turato ER. Métodos qualitativos e quantitativos na área da saúde: definições, diferenças e seus objetos de pesquisa. Rev Saude Publica 2005; 39(3):507-514.

17. Dalgalarrondo P. Psicopatologia e semiologia dos transtornos mentais. 2a ed. Porto Alegre: Artmed; 2008

18. Rosa WAG, Labate RC. A contribuição da saúde mental para o desenvolvimento do PSF. Rev Bras Enferm 2003; 53(3):230-235.

19. Amarante P. Saúde mental e atenção psicossocial. Rio de Janeiro: Editora Fiocruz; 2007.

20. Pessotti I. A loucura e as épocas. Rio de Janeiro: Editora 34; 1994 
21. Oliveira WF. Algumas Reflexões sobre as bases conceituais da Saúde Mental e a Formação do Profissional de Saúde Mental no Contexto da Promoção da Saúde. Saude Debate 2008; 32(78):38-48.

22. Amarante PDC. Loucos pela vida: a trajetória da reforma psiquiátrica no Brasil. 2a ed. Rio de Janeiro: Editora Fiocruz; 1995.

23. Brasil. Ministério da Saúde (MS). Secretaria de Gestão do Trabalho e da Educação na Saúde. Departamento de Gestão da Educação na Saúde. Projeto de Profissionalização dos Trabalhadores da Área de Enfermagem. Profissionalização de auxiliares de enfermagem: cadernos do aluno: saúde mental. Brasília: MS, Rio de Janeiro: Editora Fiocruz; 2003.

24. Costa-rosa A, Luzio C, Yasui S. Atenção psicossocial rumo a um novo paradigma na Saúde Mental Coletiva. In: Amarante P. Archivos de Saúde Mental e Atenção Psicossocial. Rio de Janeiro: Nau; 2003. p. 13-44.

25. Vecchia DM, Martins STF. Concepções dos cuidados em saúde mental por uma equipe de saúde da família, em perspectiva histórico-cultural. Cien Saude Colet 2009; 14(1):183-193.

26. Nunes M, Jucá VJ, Valentim CPB. Ações de saúde mental no Programa Saúde da Família: confluências e dissonâncias das práticas com os princípios das reformas psiquiátrica e sanitária. Cad Saude Publica 2007; 23(10):2375-2384.

27. Maciel SC, Barros DR, Camino LF, Melo JRF. Representações sociais de familiares acerca da loucura e do hospital psiquiátrico. Temas Psicol 2011; 9(1):193-204.

28. Barros LS, Cecílio LCO. Entre a 'grande política' e os autogovernos dos Agentes Comunitários de Saúde: desafios da micropolítica da atenção básica. Saude Debate 2019; 43(n. esp. 6):10-21.

29. Pereira MAO, Barbieri L, Praciano de Paula V, Franco MSP. Saúde mental no Programa de Saúde da Família: conceitos dos agentes comunitários sobre o transtorno mental. Rev Esc Enferm USP 2007; 41(4):567-572.

30. Ceccim RB, Feuerwerker LCM. O quadrilátero da formação para a área da saúde: ensino, gestão, atenção e controle social. Physys 2004; 14(1):41-65.

31. Melo EA, Miranda L, Silva AM, Limeira RMN. Dez anos dos Núcleos de Apoio à Saúde da Família (NASF): problematizando alguns desafios. Saude Debate 2018; 42(n. esp. 1):328-340.

32. Silveira DP, Vieira ALS. Saúde Mental e Atenção Básica em Saúde: análise de uma experiência no nível local. Cien Saude Colet 2009; 14(1):139-148.
33. Jucá VJ, Nunes MO, Barreto SG. Programa de Saúde da Família e Saúde Mental: impasses e desafios na construção da rede. Cien Saude Colet 2009; 14(1):173182.

34. Tanaka OY, Lauridsen-Ribeiro E. Desafio para a Atenção Básica: incorporação da assistência em saúde mental. Cad Saude Publica 2006; 22(9):1845-1853.

35. Roese A, Lopes MJM. A visita domiciliar como instrumento de coleta de dados de pesquisa e vigilância em saúde: relato de experiência. Rev Gaúch Enferm 2004; 25(1):98-111.

36. Hartz ZMA, Contandriopoulos AP. Integralidade da atenção e integração de serviços de saúde: desafios para avaliar a implantação de um "sistema sem muros”. Cad Saude Publica 2004; 20(2):331-336.

37. Barros JO, Gonçalves RMA, Kaltner RP, Lancman S. Estratégia do apoio matricial: a experiência de duas equipes do Núcleo de apoio à Saúde da Família (Nasf) da cidade de São Paulo, Brasil. Cien Saude Colet 2015; 20(9):2847-2856.

38. Dimenstein M, Severo AK, Brito M, Pimenta AL, Medeiros V, Bezerra E. O apoio matricial em unidade de saúde da família: experimentando inovações em saúde mental. Saude Soc 2009; 18(1):63-74.

39. Mendonça CS. Saúde da Família, agora mais do que nunca. Cien Saude Colet 2009; 14(Supl. 1):1493-1497.

40. Tesser CD, Poli Neto P, Campos GWS. Acolhimento e (des)medicalização social: um desafio para as equipes de saúde da família. Cien Saude Colet 2010; 15(Supl. 3):3615-3624.

Artigo apresentado em 07/07/2020

Aprovado em 28/02/2021

Versão final apresentada em 02/03/2021

Editores-chefes: Romeu Gomes, Antônio Augusto Moura da Silva 